\title{
Effect of Educational Program for Nurses Performance Regarding Infection Control Precautions, toward patient on Mechanical Ventilation.
}

\author{
Eman Abd El-Nasser Mahmoud ${ }^{1}$, Olfat Abd El-Ghany Shawer EL-shafie ${ }^{2}$, Mervat Anwar Abdel-Aziz ${ }^{3}$. \\ 1. Specialist Nursing, Faculty of Nursing, Pediatric Hospital, Assiut University, Assiut, Egypt. \\ 2. Assistant Professor of Critical \& Emergency Care Nursing, Faculty of Nursing, Assiut University, Assiut, Egypt. \\ 3. Assistant Professor of Critical \& Emergency Care Nursing, Faculty of Nursing, Assiut University, Assiut, Egypt.
}

\begin{abstract}
Background: Patients on mechanical ventilation have a greater risk of acquiring infections; however, this problem is greatest in critical care units. Aim: Evaluate effect of educational program for nurses Performance regarding to infection control standard precautions, for patients on mechanical ventilation. Study design: Quasi-experimental research design was utilized in this study. Setting: The study was conducted in trauma ICU and emergency ICU at Assiut University hospital. Sample: A convenience sample of all available nurses. The sample size was 60 nurses. Tools: Utilizing two tools, Nurse's knowledge questionnaire and Observational checklist. Results: The majority of the studied Sample statistical significant difference between before and after educational program as regard to total nurses' knowledge and practice with P-value $<0.001^{* *}$.observed nurses' knowledge scores improved from $21.7 \%$ before the educational program to $75 \%$ after the educational program. In addition, the observed nurses' practice scores improved from 21.7\% before the educational program to $71.7 \%$ after educational program. Conclusion: Nurses` knowledge and practice regarding mechanical ventilation infection Control Standard Precautions in the trauma ICU and emergency ICU becomes to the satisfactory level after the educational program. Recommendation: Nurses need for continuous training programs to increase their performance regarding mechanical ventilation infection control standard Precautions.
\end{abstract}

\section{Keywords: Educational Program, Mechanical Ventilation, Nurses Performance \& Infection Control.}

\section{Introduction}

Mechanical ventilation is a life support treatment. A mechanical ventilator is a machine that helps people breathe when they are not able $t$ o breathe enough on their own. The mechanical ventilator is also called a ventilator, respirator, or breathing machine. Most patients who need support from a ventilator because of a severe illness are cared for in hospital intensive care unit (ICU). People who need a ventilator for a longer time may be in a regular unit of a hospital, a rehabilitation facility, or cared for at home (Martin, 2017).

The sources of infection can be endogenous or exogenous infection. From organisms already harbored by patients, in ICUs usually occurs through the respiratory tract (e.g. ventilator associated pneumonia), but can also occur through the skin, especially through central venous lines or the gut. Exogenous infections are approximately $15 \%$ of all ICU- acquired infections, Which are caused by the abnormal hospital at any time during the patient stay in the ICU, usually through contact ((staff, procedures and equipment) but can also be airborne (Woodrow, 2012).

Transmission of infections in nurses facilities can be prevented and controlled through the application of basic Infection Prevention and Control precautions, which must be applied to all patients at all times, regardless of diagnosis or infectious status, and additional (transmission-based)precautions which are specific to modes of transmission-airborne, droplet and contact (Caeiro, \& Garzón, 2018).

Standard precautions are a set of infection control practices used to prevent transmission of diseases that can be acquired by contact with blood, body fluids, non-intact skin (including rashes), and mucous membranes(Gwen, 2016).

The purpose of standard precautions is to break the chain of infection focusing particularly but not exclusively on the mode of transmission, portal of entry and susceptible host sections of the chain Aseptic technique and antibiotic prophylaxis while not component of standard. Precautions are other key practices used to break the Chain of Infection at the infectious agent, reservoir and portal of exit sections of the chain.Because most people with blood borne viral infections such as HIV and HBV do not have symptoms(Schrank, \& Branch, 2017).

Nurses require in-service educational programmers to increase their performance. In addition ,continuing professional development by education and training after the point of qualification and or registration help nurses in improvement patient care and enables professional nurse practitioners to provide quality 
nursing care and service delivery to their patients(Norush et al., 2014).

\section{Significance of the study}

Mechanical ventilation is a life saving measures in critically ill patients(Olchanski et al., 2017). However, these interventions increase the risk of respiratory infections, particularly ventilatorassociated pneumonia (VAP). VAP constitutes a serious burden for nurses system and worsens the patient's outcomes; thus, several preventive have been implemented. This communication reviews the current knowledge and practice on infection and the latest preventive measures. From the researcher experience in ICU found unsatisfactory nurses' knowledge and Inadequate practices regarding infection control precaution for mechanical ventilation.

\section{Aim of the study}

The study aimed to evaluate effect of educational program for nurses Performance regarding to infection control standard precautions, for patients on mechanical ventilation

\section{Research Hypothesis}

To fulfill the aim of the study, the following research hypotheses were formulated:

- There will be significant difference between post educational program nurse's knowledge scores them the pre educational program nurse's knowledge scores.

- There will be significant difference between post educational program practices scores to the pre educational program practice scores.

\section{Subjects \& Methods}

Research design: Quasi-experimental research design had been utilized in this study pre and post tested for study and control groups.

\section{Study sample}

A convenience sample including all available nurses (60) nurses divided into (30) nurses at trauma intensive care unit and (30) nurses at emergency ICU and willing to participate in the study.

Setting: The study was carried out in trauma ICU is located in the second floor; it consists of two rooms with a total bed capacity of 13 bed and emergency ICU at Assiut university Hospital.

\section{Tools of data collection}

Two tools were developed by the researcher to collect the necessary data for this study as the following:

Tool I: Nurse's knowledge questionnaire It was developed by the researcher after reviewing the relatives and literatures(Reynolds, et al., 2017),
(Jun, et al., 2016) \& (Urner, et al., 2018). It was translated to simple Arabic language to assess exact nurse knowledge about mechanical ventilation infection control standard precautions. It was used prior to implementation of the education program. The same tool was used immediately after the implementation of the mechanical ventilation infection control standard precautions (immediate post education program). It consisted of two parts:

Part 1: Include socio-demographic data (e.g., age. gender, educational level, years of experience and pervious attended training,).

Part2:nurses' knowledge assessment: questionnaire used to assess nurses' knowledge about mechanical ventilation infection control standard precaution. It includes 5 general items as the following:

1. Knowledge about infection control contains5 list questions such as1-definition, 2- types of the infection,3- mode of transmission,4- the meaning and main objective of infection control and 5definitionof acquired infection.

2. Knowledge about Hand washing contains 9items such as purpose of hand washing, case for uses washing hands, before starting work and before leave, before wearing gloves, before and after any procedure, before and after taking the sample, after remove gloves, after contact hand with blood and any body fluid, rub all part of the hand correctly every time you work and materials used when washing hands

3. Knowledge about personal protective equipment (PPE), it consisted of 5 questions such as types of protective precaution, Wearing mask during work in ICU Wearing gown during work in ICU, Wearing gloves during give caring patient in ICU and gloves are changed between task and procedures on the same patient.

4. Knowledge about ventilator bundle care contains 7 questions such as elevate the head of the bed at 30-45 degree to unless contraindicated, changing ventilator circuit when it is visible solid, using sterile water to fill the humidifiers, perform oral hygiene with antiseptic agent every 812 hour,provide subglottic suctioning as needed, checking endotracheal tube cuff pressure every 24 hour and change suction catheter after each use.

5. Knowledge about ventilator associated pneumonia contains freely reply to the questions such as definition of mechanical ventilation, definition of ventilator associated pneumonia, nursing care of ventilator associated pneumonia.

- The structured interview questionnaire was filled out by the researcher from nurses who answered all its components then collected during theinterview.

- The total number of questions was 29. 


\section{Scoring system}

The knowledge questionnaire contains two types of questions; the first type was statements to which respondents answer with either true or false, the second type was open-ended questions where the respondents freely reply to the question. The model answers where extracted from all answer after summarizing them. A scoring system was developed. For each item two grades was awarded for the complete correct answer and one grade for noncomplete and zero for incorrect answer .The total score of the questionnaires was more than $70 \%$ were considered as having "satisfactory" knowledge level and Less than $70 \%$ were considered unsatisfactory knowledge level (Onianwa et al., 2017).

Tool II: Nurses practice standardize (Observational checklist) this tool was developed by researchers after reviewing literatures(Centers for Disease Control and Prevention (CDC), 2018) to design checklist (infection control standard precautions to all procedure for patients on mechanical ventilation).

It was applied by the researchers to assess the nurse's practice

regard infection control precautions.

It used before and immediately after the application of the infection control precautions. It consisted of:

1) Hand washing technique included 9steps.

2) Personal protective equipment (PPE) included 6steps.

3) Insertion of intravenous cannulas included 12 steps.

4) Insertion and change of intravenous lines included 12 steps.

5) Suction care included 11 steps.

6) Insertion and removal of urinary catheter included 11 steps.

7) Intubation patient care included 10 steps.

8) Ventilator care bundle included 9 steps.

9) Wound care included 11 steps.

10) Handling needles and sharps included 5 steps.

11) Environment control included 11 steps.

- Total number of questions was107-observation checklist.

\section{Scoring system}

Each step was observed, categorized and scored as follow: two degrees for each step that was done correct, one degree for each step done but incorrect method and zero for step that was not done.

The total score for all the steps was less than $(85 \%)$ were considered inadequate practical level. (85\%) or above were considered adequate practical level. considered the adequate practice level(Walker et al., 2014).

\section{Technique for data collection} Method

The study was conducted throughout three main phases, which include:

1-The preparatory phase: This phase involved: The educational program developed by the researcher was based on reviewing the relevant literature (Moralejo, et al., 2018), \& (Marschall, et al., 2017) Content validity: It was established by panel of of five expertise from the traumatic ICU and anesthesia field staff who reviewed the tools of data collection for clarity, relevance, comprehensiveness, understanding, and applicability. Modifications were made accordingly, and then the tools were designed in their final format and tested.

Reliability: knowledge assessment tool and practice assessment tools was educational program using Cronbach coefficient alpha the result of nurses' knowledge scores improved from $21.7 \%$ before the educational program to $75 \%$ after the educational program. In addition, the observed nurses' practice scores improved from $21.7 \%$ before the educational program to $71.7 \%$ after educational program.

\section{Pilot study}

It is carried out in October 2018, on six of nurses working with mechanical ventilation patients. They were chosen randomly from emergency ICU and trauma ICU at Assiut University Hospital to test visibility and applicability of the tools and to estimate the time required for interview. Some minor modifications based on the result of the pilot study were made to have more applicable tools for data collection. Some statements were omitted, added or rephrased, and then the final forms were developed, so the six of the subjects selected for the pilot study were included in the main study sample.

\section{Ethical consideration}

The research proposal was approved from the ethical committee in the faculty of nursing, There was no risk in study subject during application of the research, The study was following common ethical principles in clinical research, Data was assured for confidentiality and anonymity, Study subject had the right to refuse to participate and withdraw from the study without any rational and at any time, Study subject privacy was considered during data collection.

\section{Development of the educational program}

The researcher developed the educational program, after reviewing the literature and based on nurses identified need post the preeducational program. The following steps were adopted to develop the program. 
- Stating the content and aim of the program.

- Planning the program: the content of the program was arranged into five sessions in addition to preliminary one.

The content of the program covered two parts related to data collection tools

- Knowledge about mechanical ventilation infection control standard precautions

- The practice of the procedures regarding care of patients on Mechanical Ventilation

\section{Theoretical part included}

- Definition of infection and acquire infection, chain of infection, stage, types, modes of infection transmission and meaning of infection control.

- Definition of hand washing, purpose, hand washing routine and universal precaution of infection control

- Definition of mechanical ventilation and preventive ventilator associated pneumonia and intubation care

- Numerate ventilator bundle care (elevate the head of the bed at 30-45 degree, Perform oral hygiene every 8-12hour, etc....).

\section{Practical part included}

- Applied hand washing technique

- Applied Personal protective equipment

- Applied Insertion and change of intravenous line

- Applied Suction care procedure

- Applied nursing care of patients during Insertion and removal of urinary catheter

- nursing care of patients pre, during and post endotracheal tube insertion

- Applied Ventilator care bundle.

- Applied of Wound care.

- Applied nursing care of patients pre, during and post endotracheal tube insertion

- Implement handling needles and sharps.

- Implement environment control.

\section{Learning environment}

The program was conducted in the head nurse's office in the trauma intensive care unit and emergency intensive care unit at Assuit university hospital.

\section{Implementation phase}

Preliminary session, it contains orientation of the program and participant, distribute and fill the present sheet. Second Session include definition of infection and acquire infection, stage, types, modes of infection transmission and meaning of infection control, for 30 minutes. Third sessionincludedemonstrate of wearing and remove gloves, wearing mask and all the protective measures for 30 minutes, Four sessions include definition of hand washing, purpose, hand washing routine and explain universal precaution of infection control, Five Session include nursing care of patientpre, during and post endotracheal tube insertion, six session include Nursing care ventilator patient, ventilator bundle care and causes of ventilator associated pneumonia and preventive, for 45 minutes, Group discussion was encouraged with continuous feedback to ensure understanding and achievement of specific objectives of the educational program. Picture and video clips about the procedures were used in sessions for demonstration, in the last session; the researcher summarized and emphasized the important point's mechanical ventilation infection control standard precaution.

\section{Evaluation phase}

The last phase of proposed teaching program was the evaluation phase. In which the nurse's knowledge and practice were evaluated immediately by the researcher after mechanical ventilation infection control standard precautions implementation.

Statistical analysis

Collected data were analyzed and tabulated. The researcher used an appropriate statistical method and tests for analysis of the result. The statistical Package for (SPSS) version (23) was used to analyze data. Descriptive statistics were used for the quantitative data in questionnaire and the demographic data. Descriptive statistics included frequencies, percentages, mean, standard deviation and Pearson Correlation (Correlation is significant at the 0.05 level). The level of significance for this study was set at $(\mathrm{P} \leq 0.05)$ to detect any indication of differences found in the data available. Chi-square test used for comparison categorical variables. It was considered significant when p-values were less than 0.05. The independent t-test is an inferential statistical test that determines whether there is a statistically significant difference between the means in two unrelated groups. 


\section{Results}

Table (1): Distribution of the studied nurses is according to demographic characteristic sample $(\mathbf{n} .=60)$.

\begin{tabular}{|c|c|c|}
\hline Demographic characteristic & N.0 & $\%$ \\
\hline \multicolumn{3}{|l|}{ Qualification } \\
\hline Nursing Diploma & 23 & 38.3 \\
\hline Nursing Technician Institute & 37 & 61.7 \\
\hline \multicolumn{3}{|l|}{ Age: (years) } \\
\hline$<25 \mathrm{yrs}$ & 37 & 61.7 \\
\hline$\geq 25 \mathrm{yrs}$ & 23 & 38.3 \\
\hline \multicolumn{3}{|l|}{ Years of experience } \\
\hline$<1 \mathrm{yrs}$ & 1 & 1.7 \\
\hline $1-5 \mathrm{yrs}$ & 34 & 56.7 \\
\hline 5-10yrs & 11 & 18.3 \\
\hline $10-15 y r s$ & 13 & 21.7 \\
\hline$>15 \mathrm{yrs}$ & 1 & 1.7 \\
\hline \multicolumn{3}{|l|}{ Attending training course for infection control } \\
\hline Yes & 56 & 93.3 \\
\hline No & 4 & 6.7 \\
\hline \multicolumn{3}{|l|}{ Duration oftraining course for infection control } \\
\hline$<5 \mathrm{yrs}$ & 37 & 61.7 \\
\hline$>5 \mathrm{yrs}$ & 19 & 31.7 \\
\hline
\end{tabular}

Table (2): MeanNurses' Knowledge score regarding to infection control for patient on mechanical ventilation throughout the study phases $(n=60)$.

\begin{tabular}{|c|c|c|c|c|}
\hline \multirow[t]{2}{*}{ Nurses } & \multirow{2}{*}{$\begin{array}{c}\text { Max } \\
\text { Score }\end{array}$} & Pre & Post & \multirow{2}{*}{ P. value } \\
\hline & & Mean \pm SD & Mean \pm SD & \\
\hline Infection control & 10 & $3.48 \pm 2.02$ & $7.12 \pm 1.8$ & $<0.001 * *$ \\
\hline Personal protective equipment:- & 10 & $2.93 \pm 1.51$ & $8.28 \pm 1.25$ & $<0.001 * *$ \\
\hline Hand washing & 8 & $5 \pm 3.64$ & $7.8 \pm 1.88$ & $<0.001 * *$ \\
\hline Associated pneumonia & 6 & $2.55 \pm 1.69$ & $4.85 \pm 1.63$ & $<0.001 * *$ \\
\hline Ventilator care bundle & 14 & $3.18 \pm 2.11$ & $8.72 \pm 1.95$ & $<0.001 * *$ \\
\hline Total score of nurses' Knowledge & 48 & $17.2 \pm 10.53$ & $39.77 \pm 8.22$ & $<0.001 * *$ \\
\hline
\end{tabular}

- Independent T- test ** statistically significant difference $(p<0.01)$.

Table (3): Relation between total score of nurses' Knowledge and their demographic data before and after educational program $(n=60)$.

\begin{tabular}{|c|c|c|c|}
\hline \multirow{3}{*}{ Demographic characteristics } & \multirow{3}{*}{ N. } & \multicolumn{2}{|c|}{ total score of nurses' Knowledge } \\
\hline & & Pre & Post \\
\hline & & Mean \pm SD & Mean \pm SD \\
\hline \multicolumn{4}{|l|}{ ICU Name } \\
\hline Trauma ICU & 30 & $26.33 \pm 3.78$ & $35 \pm 0$ \\
\hline emergency ICU & 30 & $8.07 \pm 6.23$ & $24.53 \pm 8.98$ \\
\hline P. value & & $<0.001 * *$ & $<0.001 * *$ \\
\hline \multicolumn{4}{|l|}{ Qualification } \\
\hline Nursing Diploma & 23 & $16.96 \pm 10.12$ & $32 \pm 3.91$ \\
\hline Nursing Technician Institute & 37 & $17.35 \pm 10.91$ & $28.38 \pm 9.8$ \\
\hline P. value & & 0.889 & 0.097 \\
\hline \multicolumn{4}{|l|}{ Age } \\
\hline$<25 \mathrm{yrs}$ & 37 & $15.05 \pm 11.49$ & $27.11 \pm 9.48$ \\
\hline$\geq 25 \mathrm{yrs}$ & 23 & $20.65 \pm 7.83$ & $34.04 \pm 1.74$ \\
\hline P. value & & $0.044 *$ & $0.001 * *$ \\
\hline
\end{tabular}




\begin{tabular}{|c|c|c|c|}
\hline \multirow{3}{*}{ Demographic characteristics } & \multirow{3}{*}{$\mathbf{N}$. } & \multicolumn{2}{|c|}{ total score of nurses' Knowledge } \\
\hline & & Pre & Post \\
\hline & & Mean \pm SD & Mean \pm SD \\
\hline \multicolumn{4}{|l|}{ Experience } \\
\hline$<1 \mathrm{yrs}$ & 1 & $29 \pm 0$ & $35 \pm 0$ \\
\hline $1-5 y r s$ & 34 & $14.79 \pm 11.82$ & $26.59 \pm 9.69$ \\
\hline $5-10 \mathrm{yrs}$ & 11 & $20.18 \pm 4.12$ & $34.82 \pm 0.4$ \\
\hline $10-15 y r s$ & 13 & $19.38 \pm 9.96$ & $33 \pm 2.42$ \\
\hline$>15 y r s$ & 1 & $26 \pm 0$ & $35 \pm 0$ \\
\hline P. value & & 0.274 & 0.012* \\
\hline \multicolumn{4}{|l|}{ Training course for infection control } \\
\hline Yes & 56 & $16.64 \pm 10.67$ & $29.39 \pm 8.38$ \\
\hline No & 4 & $25 \pm 2.94$ & $35 \pm 0$ \\
\hline P. value & & 0.126 & 0.190 \\
\hline \multicolumn{4}{|l|}{ Duration } \\
\hline $1-5 \mathrm{yrs}$ & 37 & $16.22 \pm 11.19$ & $28.49 \pm 9.22$ \\
\hline$>5$ yrs & 19 & $17.47 \pm 9.81$ & $31.16 \pm 6.29$ \\
\hline P. value & & 0.680 & 0.263 \\
\hline
\end{tabular}

- Independent T- test $*$ Statistically significant difference $(p<0.05), * *$ statistically significant difference $(p<0.01)$.

- One Way Anova * Statistically significant difference ( $p<0.05$ ),

Table (4): Mean Nurses' practice score regarding to infection control for patient on mechanical ventilation throughout the study phases $(n=60)$.

\begin{tabular}{|l|c|c|c|c|}
\hline \multicolumn{1}{|c|}{ Practical items } & \multirow{2}{*}{ Max Score } & Pre(n=60) & Post(n=60) & \multirow{2}{*}{ P.value } \\
\cline { 3 - 4 } & & Mean \pm SD & Mean \pm SD & \\
\hline 1-Hand washing & 18 & $11.63 \pm 1.96$ & $13.27 \pm 1.87$ & $<0.001^{* *}$ \\
\hline 2-personal protective equipment & 12 & $8.53 \pm 1.82$ & $9.4 \pm 1.73$ & $0.009^{* *}$ \\
\hline 3- Insertion intravenous cannulas & 24 & $16.1 \pm 2.76$ & $18.23 \pm 2.79$ & $<0.001^{* *}$ \\
\hline 4-Intravenous lines(change/insertion) & 24 & $14.67 \pm 2.38$ & $18.5 \pm 2.28$ & $<0.001^{* *}$ \\
\hline 5-Suction care & 22 & $17.05 \pm 1.65$ & $18.37 \pm 1.94$ & $<0.001^{* *}$ \\
\hline 6-Urinary catheter & 22 & $15.85 \pm 1.96$ & $18.32 \pm 1.69$ & $<0.001^{* *}$ \\
\hline 7-Intupated patient care & 20 & $15.12 \pm 1.69$ & $15.58 \pm 1.54$ & 0.117 \\
\hline 8-Ventilator care bundle & 18 & $11 \pm 2.03$ & $14.85 \pm 1.3$ & $<0.001^{* *}$ \\
\hline 9-Dressing wound & 22 & $18.05 \pm 1.58$ & $18.7 \pm 1.53$ & $0.024^{*}$ \\
\hline 10-Needle\&sharps & 10 & $6.48 \pm 0.93$ & $6.83 \pm 0.85$ & $0.033^{*}$ \\
\hline 11-Environment control & 22 & $17.93 \pm 1.4$ & $18.53 \pm 1.27$ & $0.015^{*}$ \\
\hline Total Practice score & $\mathbf{2 1 4}$ & $\mathbf{1 5 2 . 4 2} \pm \mathbf{1 1 . 2 4}$ & $\mathbf{1 7 0 . 5 8} \pm \mathbf{1 2 . 1 7}$ & $<\mathbf{0 . 0 0 1 * *}$ \\
\hline
\end{tabular}

Independent $T$ - test $*$ Statistically significant difference $(p<0.05), * *$ statistically significant difference $(p<0.01)$.

Table (5): Relation between before and after education program related to total knowledge and practice level $(\mathrm{n}=60)$.

\begin{tabular}{|c|c|c|c|c|c|}
\hline & \multicolumn{2}{|c|}{$\operatorname{Pre}(n=60)$} & \multicolumn{2}{|c|}{ Post $(n=60)$} & \multirow{2}{*}{$P_{1}$-value } \\
\hline & N. & $\%$ & N. & $\%$ & \\
\hline \multicolumn{6}{|l|}{ Practice Level } \\
\hline Inadequate & 57 & 95.0 & 28 & 46.7 & \multirow{2}{*}{$<0.001 * *$} \\
\hline Adequate & 3 & 5.0 & 32 & 53.3 & \\
\hline \multicolumn{6}{|c|}{ Knowledge level } \\
\hline Unsatisfactory & 47 & 78.3 & 15 & 25.0 & \multirow{2}{*}{$<0.001 * *$} \\
\hline Satisfactory & 13 & 21.7 & 45 & 75.0 & \\
\hline
\end{tabular}

- Chi-square test, **Significant difference at p. value $<0.01$ 
Table (6): Relation between nurses practice score with their Socio demographic data before and after educational program $(\mathbf{n} .=60)$.

\begin{tabular}{|c|c|c|c|}
\hline \multirow{3}{*}{ Demographic characteristics } & \multirow{3}{*}{ N. } & \multicolumn{2}{|c|}{ Practice Score } \\
\hline & & Pre education & After education \\
\hline & & Mean \pm SD & Mean \pm SD \\
\hline \multicolumn{4}{|l|}{ ICU Name } \\
\hline Trauma ICU & 30 & $144.6 \pm 8.41$ & $160.2 \pm 6.24$ \\
\hline emergency ICU & 30 & $160.23 \pm 7.73$ & $180.97 \pm 6.27$ \\
\hline P.value & & $<0.001 * *$ & $<0.001 * *$ \\
\hline \multicolumn{4}{|l|}{ Qualification } \\
\hline Nursing Diploma & 23 & $151.78 \pm 9.62$ & $169 \pm 9.97$ \\
\hline Nursing Technician Institute & 37 & $152.81 \pm 12.25$ & $171.57 \pm 13.39$ \\
\hline P.value & & 0.734 & $\mathbf{0 . 4 3 2}$ \\
\hline \multicolumn{4}{|l|}{ Age } \\
\hline$<25 \mathrm{yrs}$ & 37 & $150.59 \pm 10.96$ & $169.76 \pm 12.33$ \\
\hline$\geq 25 \mathrm{yrs}$ & 23 & $155.35 \pm 11.3$ & $171.91 \pm 12.06$ \\
\hline P.value & & 0.112 & 0.509 \\
\hline \multicolumn{4}{|l|}{ Experience } \\
\hline $1-5 y r s$ & 34 & $151.74 \pm 11.34$ & $170.35 \pm 12.26$ \\
\hline $5-10 \mathrm{yrs}$ & 11 & $157.18 \pm 11.75$ & $173.27 \pm 14.85$ \\
\hline $10-15 y r s$ & 13 & $151.62 \pm 10.57$ & $170.38 \pm 10.42$ \\
\hline P.value & & 0.440 & 0.786 \\
\hline \multicolumn{4}{|c|}{ Attending training course for infection control } \\
\hline Yes & 56 & $153.39 \pm 10.95$ & $171.63 \pm 11.81$ \\
\hline No & 4 & $138.75 \pm 4.35$ & $156 \pm 7.16$ \\
\hline P.value & & 0.011* & $0.012 *$ \\
\hline \multicolumn{4}{|c|}{$\begin{array}{l}\text { Duration oftraining course for infection } \\
\text { control }\end{array}$} \\
\hline Less than one year & 37 & $153.89 \pm 11.56$ & $172.41 \pm 12.35$ \\
\hline from 1-5 year & 19 & $152.42 \pm 9.87$ & $170.11 \pm 10.84$ \\
\hline P.value & & 0.638 & 0.495 \\
\hline
\end{tabular}

- Independent T- test $*$ Statistically significant difference $(p<0.05), * *$ statistically significant difference $(p<0.01)$.

- One Way Anova

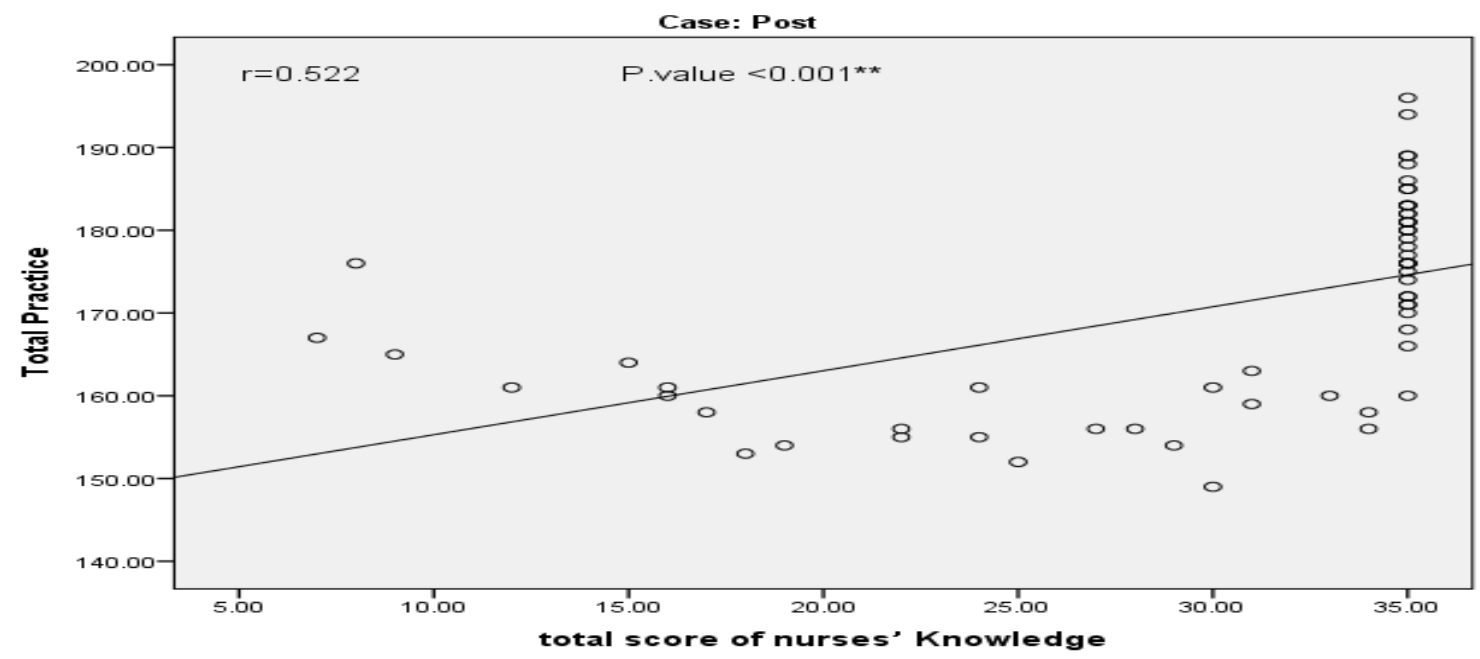

Figure (1): Correlation co- efficient between total score of nurses' knowledge and their practice after educational program $\left(n_{.}=60\right)$. 
Table (1): Showed that $50.0 \%$ of the sample was from trauma ICU, 50.0\% of the sample was from emergency ICU, it was clear that $61.7 \%$ of the studies have nursing Technician Institute and the majority of nurses 56.7 have1-5years of experiences. It was found $93.3 \%$ of nurse attending training course for infection control, duration of training course for infection control was more than half $61.7 \%$ of nurse have1-5years of work.

Table (2): Showed the relationship of the studied nurses 'knowledge regarding all knowledge component infection control, hand washing, personal protective equipment PPE, ventilator bundle care, and ventilator associated pneumoniapre and post educational program show statistical significant difference between before and after infection control precautions application. p. value $<0.001 * *$

Table (3): Revealed no statistical significant difference between before and after standard precaution application as regard to nurses 'knowledge scores with their demographic characteristics with except regarding their ages before and after infection control precautions application with $\mathrm{P}$-value 0.044* and $0.001^{* *}$ respectively and regarding their experience in years with $\mathrm{P}$-value 0.274 and $0.012 *$ respectively.

Table (4): Found a statistical significant difference between before and after infection control precautions application regard fromitem1 to item6,item8, with $\mathrm{P}$-value $<0.001^{* *}$, from item9 to item 11 with $\mathrm{P}$-value $<0.05^{*}$ and statistical significant difference between before and after infection control precautions application related to total practice.

Table (5): Found a statistical significant difference between before and after educational program as regard to total nurses' knowledge and practice with $\mathrm{P}$ value $<0.001^{* *}$ nurses' knowledge scores improved after implementation of the educational program from $21.7 \%$ to $75 \%$, Also the observed nurses' practice scores improved from $21.7 \%$ to 71.7 after implementation of the educational program.

Table (6): Showed no statistical significant difference between before and after infection control precautions applications regard nurses practical level with their demographic characteristics except attending training course for infection control with $\mathrm{P}$ value $0.032 *$.

Figure (1): Demonstrated that correlation between nurses' knowledge and their practices show that appositive correlation of the total nurses' knowledge and practice after application of infection control standard precautions.

\section{Discussion}

Infection control considers a key component of practice for all nurses, not only for their health but also to reduce nosocomial infections and thus improve the patient safety (Perveen, \& Habib, 2017).

Present study was carried out to assess the effect of implementing educational program on nurses in critical care unit

This discussion will cover the main result findings as follow:

Part I: Demographic characteristics of studied nurses

The study result revealed that more than half of nurse were in the age group less than 25 years old. this not in the same line with Ponikowski et al., (2016) who mentioned that; the administrators selected older age nurses to be able to perform mainly tasks in the intensive care unit effectively.

Concerning their educational level more than half of the studied nurses were technical institute degree. Moreover, around half of the studied nurses had experience from 1 year to 5 years. As well, (Shorofi, \& Arbon, 2017) whom revealed that the majority of nurses working in ICU have diploma of nursing, more than half of them their experience was more than 5 years.

In relation to attending any previous training program, the participant nurses attaining any previous training. This result was supported by Rochester (2017) who said that nurses who are working in the intensive care unit needs additional education to provide optimal care for patients on mechanical ventilator.

The study results added that majority of nurse attending training course for infection control, duration of training course for infection control was Less than five year.

Part II: nurses knowledge in the intensive care units regarding education Program:

Regarding nurses' knowledge about of infection control standard precautions for patient on mechanical ventilation the present study showed a statistical significant difference with p. value < $0.001 * *$ between the level of nurses' knowledge before and after implementation of the education program.

This in the same line with Friedman et al., (2017)who found the intervention significantly improved nurses' knowledge in ICU, especially for those involved in direct patient care. This increase in knowledge along with preemptive barrier precautions and active surveillance has enhanced resident safety by reducing infections in high-risk infection residents.

This result were in the same line with Shehab et al., (2018)whom concluded that more than half sector of the studied nurses had inadequate knowledge and practice regarding mechanical ventilation of critically ill adults at intensive care units. Hence, it was 
strongly recommended for need of in-service training, supervision and reinforcement for improvement of weaning knowledge and practice among nurses in the intensive care unit.

Regarding relationship between total score of nurses' Knowledge and their demographic data before and after education Program

The data of the present study showed statistical significant difference between before and after infection control standard precaution for patient on mechanical ventilation as regard to nurses' knowledge score with their socio demographic except their qualification and their training course for infection control.

Kanki, (2019) reported that each organization and profession must set standards and objectives to guide individuals and practitioners in performing safe and effective care. Also not only must standards exist, but leader and managers also must see that subordinates know and understand the standards and employee must be aware that their performance will be measured in terms of their ability to meet the established standards.

Part III: Nurses precaution regarded to infection control.

the study concluded that there was a statistical significant difference between before and after educational program for patient on mechanical ventilation regarding total nurses' practice scores. Adding, that adequate performance infection controls standard precautions which increases after application of the education.

These programs were urgently designed to assist staff nurses in developing and enhancing their skills needed to provide high standards of care to their patients. This agreed with the present study as nurse's knowledge and practice improved after implementation of the nursing intervention program.

In this respect, Michinov et al., (2016)demonstrated that educational interventions positively increased compliance with standard precautions by increasing the nurse's knowledge base and modifying their attitude and behavior.

Regarding the relationship between the total nurses' knowledge and their practice scores:

The current study found that there was a statistical significant difference in nurses' performance (knowledge and practice) after giving the educational program. This study was in the line with Ozekcin et al., (2015) who expressed that the nursing educational programs could be effective in improving the knowledge and practice among staff nurses.

Regarding the relationship between the total practice scores of the studied sample and their demographic characteristics, The study results supported the finding that applications of infection control standard precaution for patient on mechanical ventilation were effective for improving, practice of nurses in any critical care setting. Therefore, hospital administrators should provide support and resources in the form of education and training opportunities designed to increase the health care personnel awareness and application of infection control procedures.

Consequently, in this regards El-Sol, \& Badawy, (2017) emphasized that work places should have written policies about methods of utilizing infection control standard precautions to provide guidance on all aspects of critically ill patients' care. As well, continuing education regardless of age can significantly improve infection control practices and reduces rates of infection.

Regarding the correlation between nurses' Knowledge and their Practice:

Findings of the present study reported that there was a positive correlation between nurses' knowledge and practice after infection control standard precaution for patient on mechanical ventilation. This agreed with Hassan, \& Wahsheh, (2017) who indicated that there were highly significance differences through phases of study regarding knowledge and practice of nursing management of patient on mechanical ventilator. $(\mathrm{P}=0.0001)$ among studied nurses.

Finally, the findings of the present study supported the research hypothesis that nurses working emergency unit who were exposed to educational program about infection control standard precaution for patient on mechanical ventilation will show high score of knowledge and practice in the result in the of the posttest more than the pretest.

\section{Conclusions}

Nurses' knowledge regarding care of patients on Mechanical ventilator, shows that studied nurses had unsatisfactory before the educational program, compared knowledge after the educational program had satisfactory. In addition, Nurses' practice regarding care of patients on Mechanical ventilator, shows that studied nurses had inadequate practice before the educational program, compared to practice after the educational program adequate practice after the educational program. In addition, observed a positive correlation between the total score of nurses' knowledge and practice after the educational program with statistically significant differences. Level of knowledge and practice, which could reflect the lack in their scientific preparation, the educational programs prepared for the nursing staff constitute an important part in improving mechanical ventilation infection control standard precaution offered for such a group of patients. 


\section{Recommendations}

Based on the results of the present study, the following recommended: Continuous nursing education programs at critical care units should be organized within Assiut University Hospital. Nurses should add to their routine duties the regular reading to update their performance. They should always be encouraged to attend scientific meetings and conferences to keep pace with the rapid growing plenty of knowledge and practice necessary for proper effective infection control standard precaution.

\section{References}

1. Centers for Disease Control and Prevention (CDC) (2018): National Center for Emerging and Zoonotic Infectious Diseases (NCEZID), Division of Healthcare Quality Promotion (DHQP)

2. Caeiro M., Garzón, M., (2018): Controlling infectious disease outbreaks in low-income and middle-income countries. Current Treatment Options in Infectious Diseases, 10(1), 5564,pages130-138.

3. El-Sol, A., \&Badawy, A., (2017): The effect of a designed teaching module regarding prevention of central-line associated blood stream infection on ICU nurses' knowledge and practice. American Journal of Nursing Science, 6(1), 11-18.

4. Friedman, N., Carmeli, Y., Walton, A., \& Schwaber, M., (2017): Carbapenem- resistant Enterobacteriaceae: a strategic roadmap for infection control. infection control \& hospital epidemiology, 38(5), 580-594.

5. Gwen. B., (2016): infection Control Epidemiologist Wisconsin Division of Public Health Bureau of Communicable Diseases Phone 608-267-7711 Fax 608-261-4976

6. Hassan, Z., \& Wahsheh, M., (2017): Knowledge level of nurses in Jordan on ventilator-associated pneumonia and preventive measures. Nursing in critical care, 22(3), 125132.

7. Jun, J., Kovner, C., \& Stimpfel, A., (2016): Barriers and facilitators of nurses' use of clinical practice guidelines: an integrative review. International Journal of Nursing Studies, 60, 54-68.

8. Kanki, B., (2019): Communication and crew resource management. In Crew resource management (pp. 103-137).Academic Press.

9. Martin, (2017): American Thoracic Society ,mechanical ventilation, published http://www.thoracic.org
10. Michinov, E., Buffet-Bataillon, S., Chudy, C., Constant, A., Merle, V., \& Astagneau, P., (2016): Sociocognitive determinants of selfreported compliance with standard precautions: Development and preliminary testing of a questionnaire with French health care workers. American journal of infection control, 44(1), 14-19.

11. Moralejo, et al 2018: Evaluation of a staff trainingprogrammeto reimplement a comprehensive health assessment.

12. Norush, T., Van Rooyen, D., Strumpher, J., (2014): In-service education and training as experienced by registered nurses. Pubmed: 27(4):63-72.

13. Olchanski, N., Dziadzko, M., Tiong, C., Daniels, C., Peters, S., O'horo, J. C., \& Gong, M., (2017): Can a novel ICU data display positively affect patient outcomes and save lives?. Journal of medical systems, 41(11), 171.

14. Ozekcin, L., Tuite, P., Willner, K., \& Hravnak, M., (2015): Simulation education: early identification of patient physiologic deterioration by acute care nurses. Clinical Nurse Specialist, 29(3), 166-173

15. Onianwa P., Aonge T., Otegbayo J., Ike E., Chukura F., Are O., Akani O., Ayorinde M., Dubi I., \& Yaya O., (2017): Pain as $5^{\text {th }}$ sign, Impact of pain assessment training program on Nigerian nurses knowledge of pain management, International Nursing and midwifery, vol (9), P.P.129-135.

16. Ponikowski, P., Voors, A., Anker, S., Bueno, H., Cleland, J., Coats, A., \& Jessup, M., (2016): 2016 ESC Guidelines for the diagnosis and treatment of acute and chronic heart failure: The Task Force for the diagnosis and treatment of acute and chronic heart failure of the European Society of Cardiology (ESC).Developed with the special contribution of the Heart Failure Association (HFA) of the ESC. European journal of heart failure, 18(8), 891-975.

17. Perveen, S., \&Habib, S., (2017): Identifying constraints for hospital infection control management via mckinsey $7 \mathrm{~s}$ framework in Pakistan. Pakistan Journal of Public Health, 7(4), 213-222.

18. Rochester U., (2017): Bone Marrow Transplant/Hematology - EI 94, Mayo clinic, Eisenberg 94 , Bone Marrow Transplant/ Hematology , Dec 17, 2017, available on https:// www. linkedin. com/jobs/view/registered-nurse

19. Reynolds, A., Osborne, T., Waggoner, J., Melton, R., Motarjemi, R., Schulze, J., \& 
Chau, D., (2017).Advances in Health Education Technology. Using Technology to Improve Care of Older Adults, Springer Publishing Company, ch13, p287.

20. Schrank, G., \& Branch-Elliman, W., (2017): Breaking the Chain of Infection in Older Adults: A Review of Risk Factors and Strategies for Preventing Device-Related Infections. Infectious Disease Clinics, 31(4), 649-671. Cairo, J. P., \&

21. Shehab, M., Sadoon, M., Nasser, H., \& Fathy, A., (2018): Nurses Performance about Safety Weaning from Mechanical Ventilation of Critically Ill Adults and Children. International journal of Nursing Didactics, 8(11), 11-16

22. Shorofi, S., \& Arbon, P., (2017): Complementary and alternative medicine (CAM) among Australian hospital-based nurses: knowledge, attitude, personal and professional use, reasons for use, CAM referrals, and sociodemographic predictors of CAM users. Complementary therapies in clinical practice, 27, 37-45.

23. Urner, M., Ferreyro, B., Douflé, G., \& Mehta, S., (2018): Supportive Care of Patients on Mechanical Ventilation. Respiratory care, volume 63 issue (12), pp. 1567-1574.

24. Woodrow P., (2012): Intensive care nursing .Rout ledge, third edition, chapter 15

25. Walker B., Colledge N., Raston S., \& Peman I., (2014): Assessment and management of clinical problem, chapter (18), principles and practice of medicine, $22^{\text {nd }}$ ed, Elesevier, P.P. 604 